Globus pharyngeus : a review of etiology, diagnostics, and treatment

\author{
Järvenpää, Pia
}

2018-08

Järvenpää , P , Arkkila , P \& Aaltonen , L-M 2018 , ' Globus pharyngeus : a review of

etiology, diagnostics, and treatment ' , European Archives of Oto-Rhino-Laryngology, vol.

275 , no. 8 , pp. 1945-1953 . https://doi.org/10.1007/s00405-018-5041-1

http://hdl.handle.net/10138/304112

https://doi.org/10.1007/s00405-018-5041-1

publishedVersion

Downloaded from Helda, University of Helsinki institutional repository.

This is an electronic reprint of the original article.

This reprint may differ from the original in pagination and typographic detail.

Please cite the original version. 


\title{
Globus pharyngeus: a review of etiology, diagnostics, and treatment
}

\author{
Pia Järvenpää ${ }^{1}$ ( ) Perttu Arkkila ${ }^{2} \cdot$ Leena-Maija Aaltonen $^{1}$
}

Received: 17 April 2018 / Accepted: 14 June 2018 / Published online: 25 June 2018

(c) Springer-Verlag GmbH Germany, part of Springer Nature 2018

\begin{abstract}
Globus is a non-painful sensation of a lump or a foreign body in the throat, and it frequently improves with eating. Although globus is a common symptom, only little is known about the etiology, and the causes have remained controversial. Previously, globus was labelled as a hysterical symptom. However, nowadays, the research has been mainly focused on somatic causes and it is suspected that the etiology is complex. Because of the unclear etiology, the diagnostics and treatment are varying, predisposing patients to possible unnecessary investigations. This review presents the current literature of globus: its etiology, diagnostics, and treatment. In addition, a special aim is to discuss the rational investigation methods in globus diagnostics and present a diagnostic algorithm based on recent researches.
\end{abstract}

Keywords Globus pharyngeus $\cdot$ Globus diagnostics $\cdot$ Etiology $\cdot$ Treatment

\section{Introduction}

Globus (Latin globus=globe), the feeling of a lump in the throat, is a general symptom especially affecting women under 50 years. Among apparently healthy adults in a community, globus can affect $21.5-46 \%[1,2]$. The etiology of globus is disputable, leading to disagreement regarding how these patients should be examined and treated. Historically, globus was considered a psychological problem [3]. Currently, it is obvious that the causes are rather multiform, although some patients' symptoms may have a psychological background. Gastroesophageal reflux disease (GERD), laryngopharyngeal reflux (LPR), esophageal motor disorders, and improper upper esophageal sphincter (UES) function are suggested to cause globus [4-6]. However, studies demonstrating the causal relationship between these disorders and globus are mainly inadequate.

Currently, methods suitable for investigation of the esophageal etiology of globus are available. High-resolution manometry (HRM) provides more accurate diagnostics on

Pia Järvenpää

pia.jarvenpaa@fimnet.fi

1 Department of Otorhinolaryngology, Head and Neck Surgery, University of Helsinki and Helsinki University Hospital, Helsinki, Finland

2 Department of Gastroenterology, University of Helsinki and Helsinki University Hospital, Helsinki, Finland
UES pressure and in esophageal motor disorders [7]. Combined esophageal multichannel intraluminal impedance and $\mathrm{pH}$ monitoring (MII-pH) distinguishes acid and non-acid reflux, as well as allows detection of possible proximal reflux, and has the ability to define whether refluxiates are liquid, gas, or mixed [8]. Moreover, a transnasal esophagoscopy (TNE) enables a well-tolerated endoscopy to be performed under local anesthesia [9]. Recently, some studies have used these new methods to examine the esophageal background of globus.

Common treatment for globus has been to explain the benign nature of the symptom to the patient [10]. An outpatient examination has been suggested to be sufficient in patients with typical globus [11]. However, many globus patients undergo further diagnostics such as radiographic swallowing examinations. It has been proposed that attention and reassurance alleviate globus symptoms, but contrary results also exist $[12,13]$. Accordingly, some investigations may be performed to exclude a malignancy and to ensure both the patient and the clinician that the symptoms are harmless.

The aim of this review is to present the literature related to globus pharyngeus and to update the current knowledge of its etiology, diagnostics, and treatment. The review discusses the rational investigation methods based on recent research and presents an algorithm to guide in globus diagnostics. 


\section{Definition and prevalence}

Globus was already recognized in the time of Hippocrates. Historically, it was considered to be a hysterical symptom (Greek hystericus = related to uterus), globus hystericus, especially affecting anxious women [3]. In 1968, Malcomson observed that not all globus patients were hysterical or female and suggested use of the term globus pharyngeus [14].

Overall, globus seems to be equally prevalent in healthy women and men [15]. However, the symptom affects women age 50 and below three times more than men, and women are also more likely to seek medical advice regarding the symptom [15-17]. Globus represents about $4 \%$ of new referrals to ear, nose, and throat (ENT) clinics $[17,18]$. However, in one study, up to $78 \%$ of patients at other than an ENT clinics have been found to suffer from globus-like symptoms measured by the Glasgow-Edinburgh throat scale, but had never sought health care for those symptoms [19].

\section{Etiology}

\section{Gastroesophageal reflux disease}

Gastroesophageal reflux disease (GERD) is defined as a condition in which the reflux of gastric contents causes difficult symptoms and/or complications [20]. The causative role of GERD in globus is disputable. In 1968, Malcomson was the first to connect globus and GERD using barium swallow to show reflux in over $60 \%$ of globus patients [14]. Thereafter, Cherry et al. demonstrated that 10 patients out of 12 reported globus after acid was supplied to the distal esophagus [21]. Moreover, GERD was suggested to be a major cause of the symptom in up to $58 \%$ of globus patients with abnormal $\mathrm{pH}$ results [4]. However, based on an ambulatory $\mathrm{pH}$ study, in a retrospective setting, findings of GERD were not more common in patients with globus than in controls [5].

In the past decade, the association of globus symptoms with GERD has been clarified. Globus is now considered to be a manifestation of a functional esophageal disorder, and when a patient has a globus symptom directly related to reflux, the patient is considered to have GERD, even if other objective GERD findings are lacking [10]. It has been speculated that globus patients may have non-acid GERD, which would explain why they do not benefit from PPIs. However, a prospective study of Nevalainen et al. indicated that globus patients without reflux symptoms did not have acid or non-acid GERD in 24-h MII-pH [22]. Nevertheless, with the use of new advanced investigation methods, it is expected that knowledge of the causative role of GERD as an etiological factor for globus will increase.

\section{Laryngopharyngeal reflux}

Laryngopharyngeal reflux (LPR) is considered to be an extraesophageal indication of reflux disease. In LPR, the retrograde flow of gastric contents comes in contact with the mucosa of the upper aerodigestive tract [23]. In contrast to esophageal mucosa, the larynx and pharynx are very sensitive to gastric reflux, so patients with LPR are more likely to have laryngeal symptoms, such as throat cleaning, but do not necessarily have symptoms of GERD, which requires frequent and prolonged exposure to reflux [4, 24, 25]. In addition, it has been proposed that reflux could cause globus through vagus nerve. This was demonstrated in a study, where acid perfusion to the distal esophagus raised the UES pressure causing globus sensation [26]. Although hoarseness, cough, and throat cleaning are usually considered to be LPR symptoms, these symptoms are unspecific and may be caused by other disorders as well [27]. A study by Gooi et al. found that up to $48 \%$ of otolaryngologists considered LPR to be highly related to globus [6]. However, the possible connection of globus and LPR has not been clarified. The laryngeal findings indicating LPR are also unspecific and prone to under- and overestimation [28, 29]. Moreover, the prevalence of these mucosal findings suggesting reflux is reported as high as $70 \%$ in normal volunteers [30]. Therefore, the diagnostic criteria for LPR have not met with universal consensus [6].

\section{Abnormal upper esophageal sphincter function}

In 1974, Watson and Sullivan investigated globus patients and controls with manometry and found that cricopharyngeal sphincter pressure was statistically significantly higher in patients with globus [31]. However, Cook et al. found in their study of 7 globus patients and 13 healthy controls that globus patients' resting upper esophageal sphincter (UES) pressure and its response to stress were normal [32]. In a study of 32 globus patients and 24 healthy volunteers, no statistical difference was found in UES resting pressure [33]. Nonetheless, a strong association between hypertonicity of the UES and globus in conventional manometry was found in one retrospective study [5].

Currently, high-resolution manometry (HRM) is a more precise diagnostic method in the evaluation of the esophageal sphincter pressure [7]. Kwiatek et al. used HRM to quantify the timing and magnitude of respiratory variation of the UES and discovered that in globus patients, respirationrelated change in the resting UES pressure was significantly amplified compared to controls and GERD patients, but the clinical meaning of that finding is unclear [34]. However, other studies have not found the association between globus and elevated UES pressure upon HRM. In one retrospective 
study, UES basal and residual pressures between globus and dysphagia patients, as well as normal controls, were evaluated. The study showed that mean UES basal and residual pressures were normal in both globus patients and normal controls [7]. Moreover, a study by Choi et al. showed that globus patients did not have elevated UES pressure upon HRM, compared to normal controls and patients with GERD [35]. In addition, a prospective study by Nevalainen et al. found that UES pressure was not elevated in globus patients upon HRM [22].

\section{Esophageal motor disorders}

Only a limited number of studies have evaluated esophageal motor disorders as a possible cause or contributing factor in globus. In 1989, Wilson et al. demonstrated that there were no differences between globus patients' and controls' esophageal body motility upon manometry [36]. In another study, $67 \%$ of globus patients' esophageal manometry was abnormal; however, the most frequent finding (29\%) was a nonspecific esophageal motility disorder [37]. In their prospective study, Knight et al. evaluated patients with suspected extraesophageal manifestations of GERD, such as globus. Upon esophageal manometry, seven globus patients out of 12 had nonspecific esophageal disorders, while two had a hypertensive lower esophageal sphincter (LES) and three had normal results [38]. Consequently, the esophageal motor disorders most often diagnosed in globus patients have been nonspecific and made using conventional manometry. In 2016, one prospective study used a more accurate method, HRM, and it revealed an esophageal motor disorder in half of the globus patients diagnosed by the Chicago classification, the worldwide accepted algorithmic scheme to analyze HRM studies [22, 39]. However, these motor disorders were mainly minor and were similar to those that can also be detected in healthy subjects [40]. Two of their 21 globus patients had a diagnosis of a major motor disorder: one with absent peristalsis and one with esophagogastric junction outflow obstruction, a subtype of achalasia [22]. In the future, it is expected that the use of HRM may clarify the possible role of esophageal motor disorders in globus patients. However, based on Rome IV criteria if the globus patient has a diagnosis of a major esophageal motor disorder, the term globus should not be used [41].

\section{Psychological factors and stress}

Historically, the term globus hystericus was used to suggest a psychological origin to the symptom, and in fact, many studies have shown this. In a study by Deary et al., globus patients were significantly more depressed than controls [42]. Globus patients had also more stress and severe life events throughout the year compared to controls in another study [43]. Middle-aged women with globus were significantly more likely to experience neuroticism, to be less extroverted, and to have psychological distress, such as anxiety, low mood, and somatic concerns [18]. Furthermore, up to $96 \%$ of globus patients felt more symptoms when a highly emotional state occurred [1].

However, in one Finnish study, globus patients and the general population had a similar prevalence of psychiatric disorders [37]. In addition, in a study by Moser et al., mean scores were similar for anxiety, depression, hysteria, and hypochondria in globus patients compared to general medical outpatients [44]. In contrary, in a study by Tang et al., globus patients in China reported more often psychological and sleep disorders than controls [2]. Although the symptom's complex causes are accepted, it is still labelled as code $\mathrm{F} 45.8$, meaning somatoformic disorder, in the international classification of diseases, 10th edition, (ICD-10) [45].

\section{Other causes}

Conditions causing irritation or inflammation in the pharynx and larynx, such as pharyngitis and postnasal drip, may increase local sensitivity and cause globus [46]. In addition, globus may be linked to salivary hypofunction, and anticholinergic medication causing xerostomia was found to be a risk factor for globus in one cross-sectional study [47]. Anatomical causes, including tongue base hypertrophy and a retroverted epiglottis touching the posterior pharyngeal wall, have been considered as local factors inducing globus [48, 49].

Some studies have investigated thyroid pathology and globus. One-third of patients with thyroidal mass experienced globus-like symptoms before thyroid surgery [50]. In one prospective study, thyroid nodules larger than $3 \mathrm{~cm}$ located anterior to the trachea were associated with globus [51]. However, thyroidal findings, such as nodules, are common coincidence findings in healthy subjects, so their causative role in globus requires more investigation.

In 2016, a prospective study showed that in 24-h MII$\mathrm{pH}$, supragastric belching was diagnosed in globus patients more often than in controls with reflux [22]. Belching is a physiological event to release the intragastric air that one has swallowed. However, a supragastric belch is generated when a rapid suction of air into the esophagus is expelled before it reaches the stomach. Some studies suggest a relationship between supragastric belching and GERD [52]. Nevertheless, supragastric belching in globus patients is a novel finding. Different mechanisms for how a supragastric belch is created have been described. A patient may contract pharyngeal muscles to draw the air into the esophagus or breathe in through a closed glottis [53]. Speech therapy techniques have been demonstrated to alleviate symptoms in patients with supragastric belching [54]. It is possible that 
some globus patients may contract their pharyngeal muscles inappropriately because of their lump sensation, which may lead to supragastric belching. In addition, other functional causes may induce globus sensation. Globus sensation might be associated to vocal load that can induce voice disorders [55]. One study showed that some patients with persistent globus suffered from coexisting voice problems but they did not recognize that themselves [56]. Authors encouraged asking for possible voice related problems from globus patients more actively.

To exclude malignancy, many patients undergo further investigations. One retrospective study of 699 patients showed that typical globus symptoms were not hiding malignancy behind the symptom at the initial visit, whereas five patients with atypical symptoms revealed malignancies [11]. In a study by Rowley et al., none of the 74 globus patients developed an upper aerodigestive track malignancy during the 7-year follow-up. However, the study was based on a questionnaire, and if a patient noted they were symptomatic, re-examination was performed [57]. Moreover, in a study of Järvenpää et al., their national Cancer Registry data confirmed that during the 3-year follow-up, none of the 76 globus patients developed a malignancy in the upper aerodigestive tract or in the head and neck area, of which globus could have been an early symptom [58].

\section{Examinations used in globus diagnostics}

Because the etiology of globus is unclear, uniform investigation strategy is lacking. Taking a careful clinical history is essential to determine whether a patient should be referred for further investigation, such as a radiological examination or direct esophagoscopy [59]. However, globus patients without other symptoms are mainly diagnosed based on their history and a clinical examination, including neck palpation and nasolaryngoscopic examination [10]. Pathological findings in globus patients can be detected by a clinical examination with fiber-optic nasoendoscope [11]. Further investigations are not recommended when a patient has typical globus [10].

\section{Neck ultrasound}

Neck ultrasound is occasionally used in globus diagnostics. However, studies evaluating its usefulness are lacking. There are a few studies, which have assessed neck ultrasound findings in globus patients, but they have investigated only thyroid pathology [50, 51]. Järvenpää et al. reviewed the medical records in their tertiary care ENT clinic of 76 globus patients and it revealed that neck ultrasound was performed on half of their globus patients [58]. However, it was only useful in one patient who already had a palpable finding of an enlarged thyroid, which the ultrasound confirmed to be a goiter. Other neck ultrasounds were within normal limits [58].

\section{Videofluorography}

Videofluorography is quite often used in globus diagnostics, although its benefit has not been proven [60]. In 1982, Ardran examined 300 globus patients with a cineradiographic examination: patients swallowed a fluid barium suspension, showing that there was no visible lump in the throat [59]. In addition, a modified barium swallow study with esophagogram showed no benefit in globus diagnostics [61]. Moreover, Luk et al. reviewed barium swallow pharyngoesophagographies of 908 globus patients and $86 \%$ had totally normal results [62]. Authors concluded that the examination has limited diagnostic value and is, therefore, not recommended for globus patients; patients under 30 years old, in particular, had no findings. As inline with other studies, Järvenpää et al. showed that videofluorography had no benefit in globus diagnostics [58].

\section{Endoscopy}

Rigid endoscopy has been the gold standard in otorhinolaryngological practice when an endoscopic examination is needed. However, because it is an invasive investigation, it requires general anesthesia and the risk for esophagus perforation during the diagnostic endoscopic procedure has been reported to be up to $1.2 \%$ [63]. Rigid endoscopy has not been shown to be useful in globus diagnostics. Nonetheless, a survey concerning ENT consultants indicated that $61 \%$ of respondents used rigid endoscope in globus diagnostics [60]. A retrospective study of 250 globus patients examined with rigid endoscopy showed that no malignancies and the status of the larynx, pharynx, and upper esophagus were entirely normal in $87 \%$ [64].

Transnasal esophagoscopy (TNE) allows examining the upper aerodigestive tract with a thin endoscope without sedation. Shaker, a gastroenterologist, published the initial report of TNE in 1994 [65]. However, Aviv et al. were the first to publish a study of unsedated TNE in a laryngological practice [66]. The procedure is performed on a sitting patient, and after a local anesthetic is applied to the nasal cavity, the thin endoscope is passed transnasally [67]. TNE enables examination of the nasopharynx, hypopharynx, and larynx before the endoscope is passed into the esophagus, and a working channel provides an opportunity for taking biopsies [67]. TNE has been found to be safe and patients tolerate it well [67-70]. Globus is considered to be one of the indications for TNE $[67,71]$. However, in one prospective study, TNE was performed by both an otorhinolaryngologist and a gastroenterologist together and also included 
investigation of the stomach and the beginning of the duodenum, but the examination showed no benefit in globus diagnostics [22]. In that study, $10 \%$ of globus patients had endoscopic esophagitis defined by the LA Classification system $[22,72]$. However, one study among a normal population without reflux symptoms showed that esophagitis was diagnosed in 9.5\%, using gastroscopy [73]. Moreover, the biopsies, including those from the hypopharynx, did not reveal any additional findings, such as eosinophilic esophagitis in globus patients, in that sample [22]. Thus, studies have not shown that rigid nor flexible endoscopy is useful in globus diagnostics.

\section{Manometry}

Previously, a conventional manometry with five-to-eight pressure sensors was a standard investigation method used when esophageal bolus transit pathology was suspected [74]. However, patients' symptoms and manometric findings are considered to be poorly associated [75]. Currently, HRM gives more precise information about an abnormal bolus transport, esophageal motility disorders, and UES pressure $[7,74]$, and it has recently been studied in globus diagnostics $[7,34,35]$. However, recent findings upon HRM do not confirm the association between globus and elevated UES pressure nor esophageal motor disorders, and therefore, HRM is not recommended to be routinely used in globus diagnostics.

\section{pH monitoring and 24-h multichannel intraluminal impedance}

Previously, esophageal $\mathrm{pH}$ monitoring was a gold standard for investigating esophageal reflux events in GERD diagnostics [8]. However, it was not able to detect weakly acidic or non-acidic reflux. Multichannel intraluminal impedance (MII) detects all reflux events: liquid, gas, or mixed [8,76]. Moreover, when MII is combined with $\mathrm{pH}$ monitoring, it allows for detection of acid and non-acid reflux episodes and for analysing associations between a patient's symptoms and MII-pH findings [8, 77]. Recent findings, however, do not support the association of globus and GERD if patients do not suffer from concomitant heartburn [22]. As MII allows detecting aerophagia and supragastric belching, its use in the future might clarify whether globus and these disorders may be connected in some patients [22].

\section{Treatment}

Because the etiology of globus is controversial, there is no strategy regarding how to treat globus patients. PPI medication is often prescribed, because it has been suggested that globus may be related to GERD and LPR. Because exact
GERD diagnostics require invasive and expensive examinations, empirical PPI therapy to diagnose and treat possible reflux is common. GERD responds well to PPI medication, but LPR's response to this medication varies and may require higher doses and longer treatment periods $[78,79]$. One prospective, uncontrolled study demonstrated no changes in gene expression of cytokines related to inflammation when biopsies were taken from the posterior larynx tissue before and after a 10-week therapy of PPI [80]. In addition, a meta-analysis concluded that using high-dose PPIs are no more effective than placebo in the treatment of laryngopharyngeal symptoms possibly connected to GERD [81]. Moreover, placebo has been as effective as PPIs in resolving globus symptoms [82, 83].

When concomitant with disorders such a major depression or panic disorder, anti-depressants have been beneficial in resolving the globus symptoms as well, though study sample sizes were small $[84,85]$.

Globus patients with a thyroidal mass experienced improvement after thyroid surgery [50]. Moreover, globus patients with an epiglottis touching the posterior wall of the pharynx became asymptomatic after partial epiglottectomy [49]. However, both these studies lacked controls. Consequently, it is impossible to determine the operations' possible placebo effect as all surgical procedures may, themselves, have a curative effect and spontaneous recovery cannot be excluded completely.

Reducing laryngopharyngeal tension with neck and shoulder exercises, and relaxation techniques with voice hygiene and voice exercises improved $92 \%$ of globus patients' symptoms in one uncontrolled study [86]. In a sample of 36 globus patients, a speech and language pathologist (SLP) treated half of the globus patients with exercises to relieve laryngopharyngeal tension, while controls were only given reassurance by a nurse. After 3 months, patients in the SLP group had significant improvement in their symptoms compared to the control group [12]. However, whether globus patients only benefit from attention, rather than the SLP's therapy, remains ambiguous. In addition, one prospective study demonstrated that globus patients experienced recovery from their symptoms during a 4-month follow-up after an ENT physician had investigated them and they had undergone some further diagnostic procedures with normal findings [56]. This result suggests that some globus patients may benefit from assurance of the symptom's benign nature: however, this should not lead to unreasoned further examinations.

\section{Prognosis}

In globus patients, rapid symptom relief is often unlikely. During a long follow-up period of an average of 7.6 years, $55 \%$ became asymptomatic and $45 \%$ had persistent 
Fig. 1 Diagnostic algorithm for globus patients

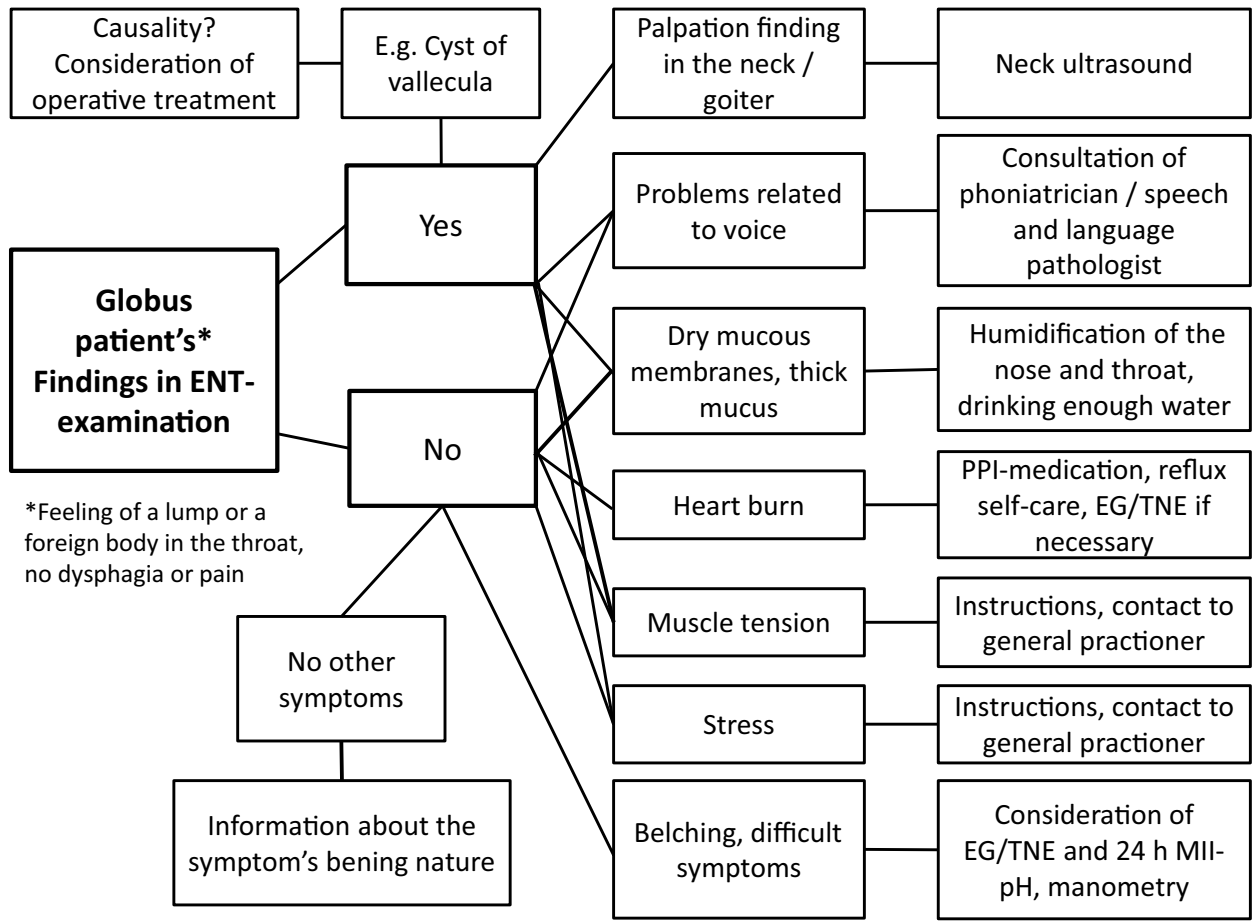

$\mathrm{ENT}=$ ear, nose and throat, $\mathrm{EG}=$ esophagogastroscopy, $\mathrm{TNE}=$ transnasal esophagoscopy, $\mathrm{PPI}=$ proton pump inhibitor, $\mathrm{MII}-\mathrm{pH}=$ multichanel intraluminal impedance and $\mathrm{pH}$-monitoring symptoms [57]. In a study with a shorter follow-up, an average of 27 months, $50 \%$ of patients became asymptomatic or experienced symptom relief [87]. Male gender, short duration of the globus symptom, and no other throat symptoms were associated with rapid resolution of symptoms [87]. In a study by Järvenpää et al. globus patients received a questionnaire concerning their present symptoms 3 and 6 years after the initial visit at ENT clinic [58]. At both follow-ups, approximately half of the patients reported that they were asymptomatic or that they had fewer symptoms than at the initial visit [58]. However, almost half of the patients felt that their symptoms were the same at follow-ups [58].

\section{Discussion}

The recent literature confirms that not only one cause can explain a globus patient's symptoms, but also the background is multifaceted. PPIs have been widely used to treat globus, perhaps as a trial to diagnose silent reflux. However, the current literature does not support the assumption that GERD is the main cause for globus. In addition, high-dose PPIs are no more effective than placebo in the treatment of globus. As PPIs may have long-term side-effects, the use of this medication requires justification. However, if the patient has concomitant heartburn, the diagnostics and treatment should direct to GERD.
Neck ultrasound is not useful in globus diagnostics if neck palpation is normal. In addition, globus patients do not benefit from videofluorography as they lack swallowing difficulties. Currently, new investigation methods, such as HRM and 24-h MII-pH, enable more accurate diagnostics and further studies will clarify whether supragastric belching, aerophagia or major esophageal motor disorders are overrepresented in globus patients. This knowledge would also enhance the available treatment options, since treatment until now has mainly been to give reassurance to the patients. However, these new investigations are not recommended to be used in clinical routine.

Based on the literature, globus patients without alarming symptoms, such as pain or swallowing difficulties, and who have no findings in ENT examination including nasolaryngoscopic examination and neck palpation, require no further examinations. However, analysing patient history carefully may reveal a globus patient's concomitant voice problem, stress or tension in the neck, and in these cases, the diagnostics and treatment should focus on these issues. Most of the patients suffer from mild and intermittent globus symptoms and it is known that many patients' symptoms alleviate without any treatment. The most important thing is to explain the patient the symptom's natural course and advise to contact again if the symptoms become severe or progressive, or if other symptoms such as pain or dysphagia occur. 


\section{Conclusion}

The patient history and clinical ENT examination are the most important tolls also in globus diagnostics. Following a diagnostic algorithm may be helpful to decide how to proceed with diagnostics (Fig. 1). Although some examinations are performed to convince the patient, and sometimes the clinician, that the globus is harmless, it is assumed that a patient will be satisfied if the clinician explains why further examinations are not necessary in most of the cases.

\section{Compliance with ethical standards}

Conflict of interest All authors have no conflict of interest.

Human and animal rights statement This article is a review article within which there are no human participants or animals. Informed consent is not available in this article.

\section{References}

1. Thompson WG, Heaton KW (1982) Heartburn and globus in apparently healthy people. Can Med Assoc J 126:46-48

2. Tang B, Cai HD, Xie HL, Chen DY, Jiang SM, Jia L (2016) Epidemiology of globus symptoms and associated psychological factors in China. J Dig Dis 17:319-324

3. Merskey H, Merskey SJ (1993) Hysteria, or "suffocation of the mother". CMAJ 148:399-405

4. Koufman JA (1991) The otolaryngologic manifestations of gastroesophageal reflux disease (GERD): a clinical investigation of 225 patients using ambulatory 24-hour $\mathrm{pH}$ monitoring and an experimental investigation of the role of acid and pepsin in the development of laryngeal injury. Laryngoscope 101:1-78

5. Corso MJ, Pursnani KG, Mohiuddin MA, Gideon RM, Castell JA, Katzka DA, Katz PO, Castell DO (1998) Globus sensation is associated with hypertensive upper esophageal sphincter but not with gastroesophageal reflux. Dig Dis Sci 43:1513-1517

6. Gooi Z, Ishman SL, Bock JM, Blumin JH, Akst LM (2014) Laryngopharyngeal reflux: paradigms for evaluation, diagnosis, and treatment. Ann Otol Rhinol Laryngol 123:677-685

7. Peng L, Patel A, Kushnir V, Gyawali CP (2015) Assessment of upper esophageal sphincter function on high-resolution manometry: identification of predictors of globus symptoms. J Clin Gastroenterol 49:95-100

8. Zerbib F, Roman S, Ropert A, des Varannes SB, Pouderoux P, Chaput U, Mion F, Verin E, Galmiche JP, Sifrim D (2006) Esophageal $\mathrm{pH}$-impedance monitoring and symptom analysis in GERD: a study in patients off and on therapy. Am J Gastroenterol 101:1956-1963

9. Postma GN (2006) Transnasal esophagoscopy. Curr Opin Otolaryngol Head Neck Surg 14:156-158

10. Galmiche JP, Clouse RE, Balint A, Cook IJ, Kahrilas PJ, Paterson WG, Smout AJ (2006) Functional esophageal disorders. Gastroenterology 130:1459-1465

11. Harar RP, Kumar S, Saeed MA, Gatland DJ (2004) Management of globus pharyngeus: review of 699 cases. J Laryngol Otol 118:522-527

12. Khalil HS, Bridger MW, Hilton-Pierce M, Vincent J (2003) The use of speech therapy in the treatment of globus pharyngeus patients. A randomised controlled trial. Rev Laryngol Otol Rhinol (Bord) 124:187-190

13. Millichap F, Lee M, Pring T (2005) A lump in the throat: should speech and language therapists treat globus pharyngeus? Disabil Rehabil 27:124-130

14. Malcomson KG (1968) Globus hystericus vel pharyngis (a recommaissance of proximal vagal modalities). J Laryngol Otol $82: 219-230$

15. Batch AJ (1988) Globus pharyngeus (Part I). J Laryngol Otol 102:152-158

16. Moloy PJ, Charter R (1982) The globus symptom. Incidence, therapeutic response, and age and sex relationships. Arch Otolaryngol 108:740-744

17. Rasmussen ER, Schnack DT, Ravn AT (2018) A prospective cohort study of 122 adult patients presenting to an otolaryngologist's office with globus pharyngeus. Clin Otolaryngol. https://doi. org/10.1111/coa.13065

18. Deary IJ, Wilson JA, Kelly SW (1995) Globus pharyngis, personality, and psychological distress in the general population. Psychosomatics 36:570-577

19. Ali KH, Wilson JA (2007) What is the severity of globus sensation in individuals who have never sought health care for it? J Laryngol Otol 121:865-868

20. Vakil N, van Zanten SV, Kahrilas P, Dent J, Jones R, Global Consensus Group (2006) The Montreal definition and classification of gastroesophageal reflux disease: a global evidence-based consensus, Am J Gastroenterol 101:1900-1920 (quiz 1943)

21. Cherry J, Siegel CI, Margulies SI, Donner M (1970) Pharyngeal localization of symptoms of gastroesophageal reflux. Ann Otol Rhinol Laryngol 79:912-914

22. Nevalainen P, Walamies M, Kruuna O, Arkkila P, Aaltonen L (2016) Supragastric belch may be related to globus symptom-a prospective clinical study. Neurogastroenterol Motil 28:680-686

23. Ford CN (2005) Evaluation and management of laryngopharyngeal reflux. JAMA 294:1534-1540

24. Koufman J, Sataloff RT, Toohill R (1996) Laryngopharyngeal reflux: consensus conference report. J Voice 10:215-216

25. Phua SY, McGarvey LP, Ngu MC, Ing AJ (2005) Patients with gastro-oesophageal reflux disease and cough have impaired laryngopharyngeal mechanosensitivity. Thorax 60:488-491

26. Tokashiki R, Funato N, Suzuki M (2010) Globus sensation and increased upper esophageal sphincter pressure with distal esophageal acid perfusion. Eur Arch Otorhinolaryngol 267:737-741

27. Tauber S, Gross M, Issing WJ (2002) Association of laryngopharyngeal symptoms with gastroesophageal reflux disease. Laryngoscope 112:879-886

28. Kelchner LN, Horne J, Lee L, Klaben B, Stemple JC, Adam S, Kereiakes T, Levin L (2007) Reliability of speech-language pathologist and otolaryngologist ratings of laryngeal signs of reflux in an asymptomatic population using the reflux finding score. J Voice 21:92-100

29. Musser J, Kelchner L, Neils-Strunjas J, Montrose M (2011) A comparison of rating scales used in the diagnosis of extraesophageal reflux. J Voice 25:293-300

30. Hicks DM, Ours TM, Abelson TI, Vaezi MF, Richter JE (2002) The prevalence of hypopharynx findings associated with gastroesophageal reflux in normal volunteers. J Voice 16:564-579

31. Watson WC, Sullivan SN (1974) Hypertonicity of the cricopharyngeal sphincter: a cause of globus sensation. Lancet 2:1417-1419

32. Cook IJ, Dent J, Collins SM (1989) Upper esophageal sphincter tone and reactivity to stress in patients with a history of globus sensation. Dig Dis Sci 34:672-676

33. Sun J, Xu B, Yuan YZ, Xu JY (2002) Study on the function of pharynx upper esophageal sphincter in globus hystericus. World J Gastroenterol 8:952-955 
34. Kwiatek MA, Mirza F, Kahrilas PJ, Pandolfino JE (2009) Hyperdynamic upper esophageal sphincter pressure: a manometric observation in patients reporting globus sensation. Am J Gastroenterol 104:289-298

35. Choi WS, Kim TW, Kim JH, Lee SH, Hur WJ, Choe YG, Lee SH, Park JH, Sohn CI (2013) High-resolution manometry and globus: comparison of globus, gastroesophageal reflux disease and normal controls using high-resolution manometry. J Neurogastroenterol Motil 19:473-478

36. Wilson JA, Pryde A, Piris J, Allan PL, Macintyre CC, Maran AG, Heading RC (1989) Pharyngoesophageal dysmotility in globus sensation. Arch Otolaryngol Head Neck Surg 115:1086-1090

37. Farkkila MA, Ertama L, Katila H, Kuusi K, Paavolainen M, Varis K (1994) Globus pharyngis, commonly associated with esophageal motility disorders. Am J Gastroenterol 89:503-508

38. Knight RE, Wells JR, Parrish RS (2000) Esophageal dysmotility as an important co-factor in extraesophageal manifestations of gastroesophageal reflux. Laryngoscope 110:1462-1466

39. Bredenoord AJ, Fox M, Kahrilas PJ, Pandolfino JE, Schwizer W, Smout AJ, International High Resolution Manometry Working Group (2012) Chicago classification criteria of esophageal motility disorders defined in high resolution esophageal pressure topography. Neurogastroenterol Motil 24(Suppl 1):57-65

40. Kahrilas PJ, Bredenoord AJ, Fox M, Gyawali CP, Roman S, Smout AJ, Pandolfino JE, International High Resolution Manometry Working Group (2015) The Chicago classification of esophageal motility disorders, v3.0. Neurogastroenterol Motil 27:160-174

41. Aziz Q, Fass R, Gyawali CP, Miwa H, Pandolfino JE, Zerbib F (2016) Functional esophageal disorders. Gastroenterology 150:1368-1379

42. Deary IJ, Smart A, Wilson JA (1992) Depression and 'hassles' in globus pharyngis. Br J Psychiatry 161:115-117

43. Harris MB, Deary IJ, Wilson JA (1996) Life events and difficulties in relation to the onset of globus pharyngis. J Psychosom Res 40:603-615

44. Moser G, Vacariu-Granser GV, Schneider C, Abatzi TA, Pokieser P, Stacher-Janotta G, Gaupmann G, Weber U, Wenzel T, Roden M (1991) High incidence of esophageal motor disorders in consecutive patients with globus sensation. Gastroenterology 101:1512-1521

45. Word Health Organization (2016) International classification of diseases and related health problems, 10th revision. http://www. who.int/classifications/icd/en/. Accessed 25 Oct 2017

46. Batch AJ (1988) Globus pharyngeus: (part II), discussion. J Laryngol Otol 102:227-230

47. Haft S, Carey RM, Farquhar D, Mirza N (2016) Anticholinergic medication use is associated with globus pharyngeus. J Laryngol Otol 130:1125-1129

48. Mamede RC, De Mello-Filho FV, Dantas RO (2004) Severe hypertrophy of the base of the tongue in adults. Otolaryngol Head Neck Surg 131:378-382

49. Agada FO, Coatesworth AP, Grace AR (2007) Retroverted epiglottis presenting as a variant of globus pharyngeus. J Laryngol Otol 121:390-392

50. Burns P, Timon C (2007) Thyroid pathology and the globus symptom: are they related? A two year prospective trial. J Laryngol Otol 121:242-245

51. Nam IC, Choi H, Kim ES, Mo EY, Park YH, Sun DI (2015) Characteristics of thyroid nodules causing globus symptoms. Eur Arch Otorhinolaryngol 272:1181-1188

52. Hemmink GJ, Bredenoord AJ, Weusten BL, Timmer R, Smout AJ (2009) Supragastric belching in patients with reflux symptoms. Am J Gastroenterol 104:1992-1997

53. Bredenoord AJ (2010) Excessive belching and aerophagia: two different disorders. Dis Esophagus 23:347-352
54. Hemmink GJ, Ten Cate L, Bredenoord AJ, Timmer R, Weusten BL, Smout AJ (2010) Speech therapy in patients with excessive supragastric belching - a pilot study, Neurogastroenterol Motil 22:24-28 (e2-3)

55. Luyten A, Bruneel L, Meerschman I, D'haeseleer E, Behlau M, Coffe C, Van Lierde K (2016) Prevalence of vocal tract discomfort in the flemish population without self-perceived voice disorders. J Voice 30:308-314

56. Jarvenpaa P, Laatikainen A, Roine RP, Sintonen H, Arkkila P, Aaltonen LM (2017) Symptom relief and health-related quality of life in globus patients: a prospective study. Logoped Phoniatr Vocol. https://doi.org/10.1080/14015439.2017.1397741

57. Rowley H, O'Dwyer TP, Jones AS, Timon CI (1995) The natural history of globus pharyngeus. Laryngoscope 105:1118-1121

58. Jarvenpaa P, Ilmarinen T, Geneid A, Pietarinen P, Kinnari TJ, Rihkanen H, Ruohoalho J, Markkanen-Leppanen M, Back L, Arkkila P, Aaltonen LM (2017) Work-up of globus: assessing the benefits of neck ultrasound and videofluorography. Eur Arch Otorhinolaryngol 274:931-937

59. Ardran GM (1982) Feeling of a lump in the throat: thoughts of a radiologist. J R Soc Med 75:242-244

60. Webb CJ, Makura ZG, Fenton JE, Jackson SR, McCormick MS, Jones AS (2000) Globus pharyngeus: a postal questionnaire survey of UK ENT consultants. Clin Otolaryngol Allied Sci 25:566-569

61. Dworkin JP, Dowdall JR, Kubik M, Thottam PJ, Folbe A (2015) The role of the modified barium swallow study and esophagram in patients with globus sensation. Dysphagia 30:506-510

62. Luk WH, Lo AX, Au-Yeung AW, Lai MH, Woo YH, Wong LK, Chiang CC (2014) The role of barium swallow pharyngoesophagography in the management of the globus pharyngeus: our ten years local experience of asian population. Indian J Otolaryngol Head Neck Surg 66:153-155

63. Kubba H, Spinou E, Brown D (2003) Is same-day discharge suitable following rigid esophagoscopy? Findings in a series of 655 cases. Ear Nose Throat J 82:33-36

64. Takwoingi YM, Kale US, Morgan DW (2006) Rigid endoscopy in globus pharyngeus: how valuable is it? J Laryngol Otol 120:42-46

65. Shaker R (1994) Unsedated trans-nasal pharyngoesophagogastroduodenoscopy (T-EGD): technique. Gastrointest Endosc 40:346-348

66. Aviv JE, Takoudes TG, Ma G, Close LG (2001) Office-based esophagoscopy: a preliminary report. Otolaryngol Head Neck Surg 125:170-175

67. Postma GN, Cohen JT, Belafsky PC, Halum SL, Gupta SK, Bach KK, Koufman JA (2005) Transnasal esophagoscopy: revisited (over 700 consecutive cases). Laryngoscope 115:321-323

68. Dean R, Dua K, Massey B, Berger W, Hogan WJ, Shaker R (1996) A comparative study of unsedated transnasal esophagogastroduodenoscopy and conventional EGD. Gastrointest Endosc 44:422-424

69. Thota PN, Zuccaro G Jr, Vargo JJ 2nd, Conwell DL, Dumot JA, $\mathrm{Xu}$ M (2005) A randomized prospective trial comparing unsedated esophagoscopy via transnasal and transoral routes using a 4-mm video endoscope with conventional endoscopy with sedation. Endoscopy 37:559-565

70. Streckfuss A, Bosch N, Plinkert PK, Baumann I (2014) Transnasal flexible esophagoscopy (TNE): an evaluation of the patient's experience and time management. Eur Arch Otorhinolaryngol 271:323-328

71. Amin MR, Postma GN, Setzen M, Koufman JA (2008) Transnasal esophagoscopy: a position statement from the American Bronchoesophagological Association (ABEA). Otolaryngol Head Neck Surg 138:411-414

72. Lundell LR, Dent J, Bennett JR, Blum AL, Armstrong D, Galmiche JP, Johnson F, Hongo M, Richter JE, Spechler SJ, 
Tytgat GN, Wallin L (1999) Endoscopic assessment of oesophagitis: clinical and functional correlates and further validation of the Los Angeles classification. Gut 45:172-180

73. Ronkainen J, Aro P, Storskrubb T, Lind T, Bolling-Sternevald E, Junghard O, Talley NJ, Agreus L (2006) Gastro-oesophageal reflux symptoms and health-related quality of life in the adult general population - the Kalixanda study. Aliment Pharmacol Ther 23:1725-1733

74. Fox M, Hebbard G, Janiak P, Brasseur JG, Ghosh S, Thumshirn M, Fried M, Schwizer W (2004) High-resolution manometry predicts the success of oesophageal bolus transport and identifies clinically important abnormalities not detected by conventional manometry. Neurogastroenterol Motil 16:533-542

75. Kahrilas PJ, Clouse RE, Hogan WJ (1994) American Gastroenterological Association technical review on the clinical use of esophageal manometry. Gastroenterology 107:1865-1884

76. Sifrim D, Silny J, Holloway RH, Janssens JJ (1999) Patterns of gas and liquid reflux during transient lower oesophageal sphincter relaxation: a study using intraluminal electrical impedance. Gut 44:47-54

77. Vela MF, Camacho-Lobato L, Srinivasan R, Tutuian R, Katz PO, Castell DO (2001) Simultaneous intraesophageal impedance and $\mathrm{pH}$ measurement of acid and nonacid gastroesophageal reflux: effect of omeprazole. Gastroenterology 120:1599-1606

78. Katz PO, Castell DO (2000) Medical therapy of supraesophageal gastroesophageal reflux disease. Am J Med 108(Suppl 4a):170S-177S

79. Park W, Hicks DM, Khandwala F, Richter JE, Abelson TI, Milstein C, Vaezi MF (2005) Laryngopharyngeal reflux: prospective cohort study evaluating optimal dose of proton-pump inhibitor therapy and pretherapy predictors of response. Laryngoscope 115:1230-1238

80. Thibeault SL, Smith ME, Peterson K, Ylitalo-Moller R (2007) Gene expression changes of inflammatory mediators in posterior laryngitis due to laryngopharyngeal reflux and evolution with PPI treatment: a preliminary study. Laryngoscope 117:2050-2056

81. Gatta L, Vaira D, Sorrenti G, Zucchini S, Sama C, Vakil N (2007) Meta-analysis: the efficacy of proton pump inhibitors for laryngeal symptoms attributed to gastro-oesophageal reflux disease. Aliment Pharmacol Ther 25:385-392

82. Noordzij JP, Khidr A, Evans BA, Desper E, Mittal RK, Reibel JF, Levine PA (2001) Evaluation of omeprazole in the treatment of reflux laryngitis: a prospective, placebo-controlled, randomized, double-blind study. Laryngoscope 111:2147-2151

83. Vaezi MF, Richter JE, Stasney CR, Spiegel JR, Iannuzzi RA, Crawley JA, Hwang C, Sostek MB, Shaker R (2006) Treatment of chronic posterior laryngitis with esomeprazole. Laryngoscope 116:254-260

84. Brown SR, Schwartz JM, Summergrad P, Jenike MA (1986) Globus hystericus syndrome responsive to antidepressants. Am J Psychiatry 143:917-918

85. Cybulska EM (1997) Globus hystericus-a somatic symptom of depression? The role of electroconvulsive therapy and antidepressants. Psychosom Med 59:67-69

86. Wareing M, Elias A, Mitchell D (1997) Management of globus sensation by the speech therapist. Logoped Phoniatr Vocol 22:39-42

87. Timon C, O’Dwyer T, Cagney D, Walsh M (1991) Globus pharyngeus: long-term follow-up and prognostic factors. Ann Otol Rhinol Laryngol 100:351-354 